\title{
IMPACT OF ENVIRONMENTAL CONDITIONS ON THE CAPACITY OF POWER LINES
}

\author{
Michal ŠPES*, L'ubomír BEŇA*, Michal KOSTEREC*, Lukáš KRUŽELÁK*, Zdeněk MÜLLER**, \\ Henryk WACHTA $^{* * *}$, Michal MÁRTON ${ }^{* * * *}$ \\ *Department of Electrical Power Engineering, Faculty of Electrical Engineering and Informatics, \\ Technical University of Košice, Mäsiarska 74, 04120 Košice, Slovak Republic, Tel.: +421 556023560 , \\ E-mail:michal.spes@tuke.sk, lubomir.bena@tuke.sk, michal.kosterec@tuke.sk, lukas.kruzelak@tuke.sk \\ ${ }^{* *}$ Department of Electrical Power Engineering, Faculty of Electrical Engineering, Czech Technical University in Prague, \\ Prague, Czech Republic, E-mail: zdenek.muller@fel.cvut.cz \\ ${ }^{* * *}$ Department of Power Electronics, Power Engineering and Complex Systems, Faculty of Electrical and Computer Engineering, \\ Rzeszow University of Technology, W. Pola 2, 35-959 Rzeszow, Poland, Tel.: +48 17865 1977, E-mail: hwachta@prz.edu.pl \\ ***** Department of Electronics and Multimedia Telecommunications, Faculty of Electrical Engineering and Informatics, Technical \\ University of Košice, Vysokoškolská 4, 04001 Košice, Slovak Republic, E-mail: michal.marton@tuke.sk
}

\begin{abstract}
This article deals with determining the value of maximum permissible current with consideration of ambient conditions. Each ambient conditions and their influence on the value of current ampacity for ACSR conductor 350/59 in comparison with ampacity given by calculation accordance the standard EN 50341 are described in this article. Static ambient conditions are given in this standard and change in the ambient conditions was neglected in calculation of the resulting value. The aim of this article is to refer the influence of the change of ambient environment and ambient conditions to the maximum permissible current.
\end{abstract}

Keywords: ACSR 350/59, capacity of conductor, maximum permissible value of current, ambient conditions, intensity of solar radiation, air velocity, ambient temperature, angle of wind impact

\section{INTRODUCTION}

Extensive development of renewable sources requires expansion of transmission capacity of power lines. Despite the fact that power lines are an integral part of the system but their expansion is in seclusion interests. For these reasons, it is necessary to seek other means of safeguarding the power transmission system. One of the possibility is using of operational methods which monitor the temperature of the electrical wire and ambient influences. These indicate the current permissible current. To determine the allowable current of the conductor is necessary to determine all factors influencing temperature of the conductor. Subsequent calculation can be determined at any time under the conditions of maximum load capacity.

\section{CONDUCTOR AMPACITY}

Ampacity of overhead power lines is defined as the transmission capacity or as maximum permissible current, which can be transmitted through the conductor without compromising its function. The disruption of its function is mainly caused by exceeding the maximum permissible operating temperature [1] [2] [3].

The maximum current that can be transferred over the line, is not a constant value, but is determined for the changing temperature of conductors depending on ambient conditions - particularly ambient temperature and wind flow [3].

The ampacity depends on:

- electrical and mechanical properties of the conductor material,

- thermal insulation properties (cables),
- ability to dissipate generated heat within the conductor received heat from surrounding environment,

- ambient weather conditions [4].

It is apparent that the ampacity is mainly influenced by the thermal condition of the conductors, because it determines the stretch of conductors and the sag of overhead power line.

Method that is based on the thermal equilibrium between the conductors and the environment was used to determine the maximum transmission capacity [5] [6].

At steady state, this equation can be expressed as equality heat gain $=$ heat loss [6] [7].

The full form of the equation is:

$$
P_{J}+P_{M}+P_{S}+P_{i}=P_{C}+P_{r}+P_{W}
$$

Where:

$P_{J}(\mathrm{~W})$ - heat losses in the conductor,

$P_{M}(\mathrm{~W})$ - magnetic heating of magnetic field variations

$\mathrm{AC}$,

$P_{S}(\mathrm{~W})$ - solar radiation,

$P_{i}(\mathrm{~W})$ - corona heating,

$P_{C}(\mathrm{~W})$ - cooling by heat convection - by radiation,

$P_{r}(\mathrm{~W})$ - radiant cooling,

$P_{W}(\mathrm{~W})$ - cooling from water evaporation.

Corona heating $P_{i}$, cooling by evaporation of water $P_{W}$ and heating by changing the magnetic field of alternating current $P_{M}$ are usually neglected, then the final equation is as follows [8] [9].

$P_{J}+P_{S}=P_{C}+P_{r}$ 
Detailed description of the method of calculation is given in the literature [10].

The most commonly used conductors are ACSR ropes. Manufacturers of conductors indicate maximum operating temperature of conductor $90{ }^{\circ} \mathrm{C}$ to $100{ }^{\circ} \mathrm{C}$. In the case of temperature exceeding, the lifetime of conductor is reduced. Conductor temperature depends on the ambient conditions and the value of passing current [7].

Power lines designed by the current applicable standard EN 50341 are controlled by the designed maximum conductor temperature within the project documentation. Recommended temperature of the conductor is $70{ }^{\circ} \mathrm{C}$. In the case where the highest phase current of conductor is stated, it is possible to calculate the actual temperature of conductor [11].

The calculation is made for the following conditions:

- the conductor is at maximum load,

- the ambient temperature is $35^{\circ} \mathrm{C}$,

- wind speed is $0.5 \mathrm{~m} / \mathrm{s}$ at $45^{\circ}$ angle of impact,

- global temperature solar radiation is $1000 \mathrm{~W} / \mathrm{m}^{2}$,

- absorption coefficient is 0.5 [11].

\section{CONSTRUCTRION OF ULTRA HIGH VOLTAGE POWER LINES}

The term ultra high voltage power lines is meant for lines of $400 \mathrm{kV}$ voltage level in the Slovak Republic. This power lines belong to the transmission lines which provide transmission of power from sources to the distribution power system. Transmission lines ensure cross-border transfer with member states of ENTSO-E.

Transmission power system of Slovak Republic is in the following figure (Fig. 1).

The construction of power lines has to be designed for high power and currents. Used conductors are connected into the bundle, where one phase of power lines usually consists of three bunched conductors. This conductors are connected to each other electrically and mechanically. The bundle composed of three conductors creates an electric field as one conductor with equivalent radius.

The most commonly used conductors in transmission power system are ACSR conductors. The core of this conductors is a steel and material used for wires is an aluminium.

Their advantages include greater flexibility and more uniform structure. Material mistake can damage the whole wire, but with ACSR ropes the tear of one wire does not lead to damaging the whole conductor. ACSR cables are also used as a grounding conductors, which can be supplemented by optical fibre to ensure communication between devices.

Parameters of the examined ACSR conductor are in the following table.

Table 1 Parameters of the conductor ACSR 350/59 [12]

\begin{tabular}{|l|l|}
\hline type of conductor & ACSR 350/59 \\
\hline diameter $(\mathrm{mm})$ & 26.39 \\
\hline rope cross-section $\left(\mathrm{mm}^{2}\right)$ & 410.8 \\
\hline nominal weight $\left(\mathrm{kg} \cdot \mathrm{km}^{-1}\right)$ & 1453.01 \\
\hline specific gravity $\left(\mathrm{MN} \cdot \mathrm{m}^{-3}\right)$ & 0.03469 \\
\hline $\begin{array}{l}\text { maximum permissible stresses } \\
(\mathrm{MPa})\end{array}$ & 108.661 \\
\hline elastic modulus $(\mathrm{MPa})$ & 74332 \\
\hline $\begin{array}{l}\text { coefficient of thermal expansion } \\
\left(1 /{ }^{\circ} \mathrm{C}\right)\end{array}$ & 18.65 \\
\hline rated DC resistance $(\Omega / \mathrm{km})$ & 0.0835 \\
\hline
\end{tabular}

\section{RESEARCH PROBLEMS DEFINITION}

As mentioned in the previous chapter, the design of lines is based on the static ambient conditions and therefore lines are designed for the worst case of climatic conditions.

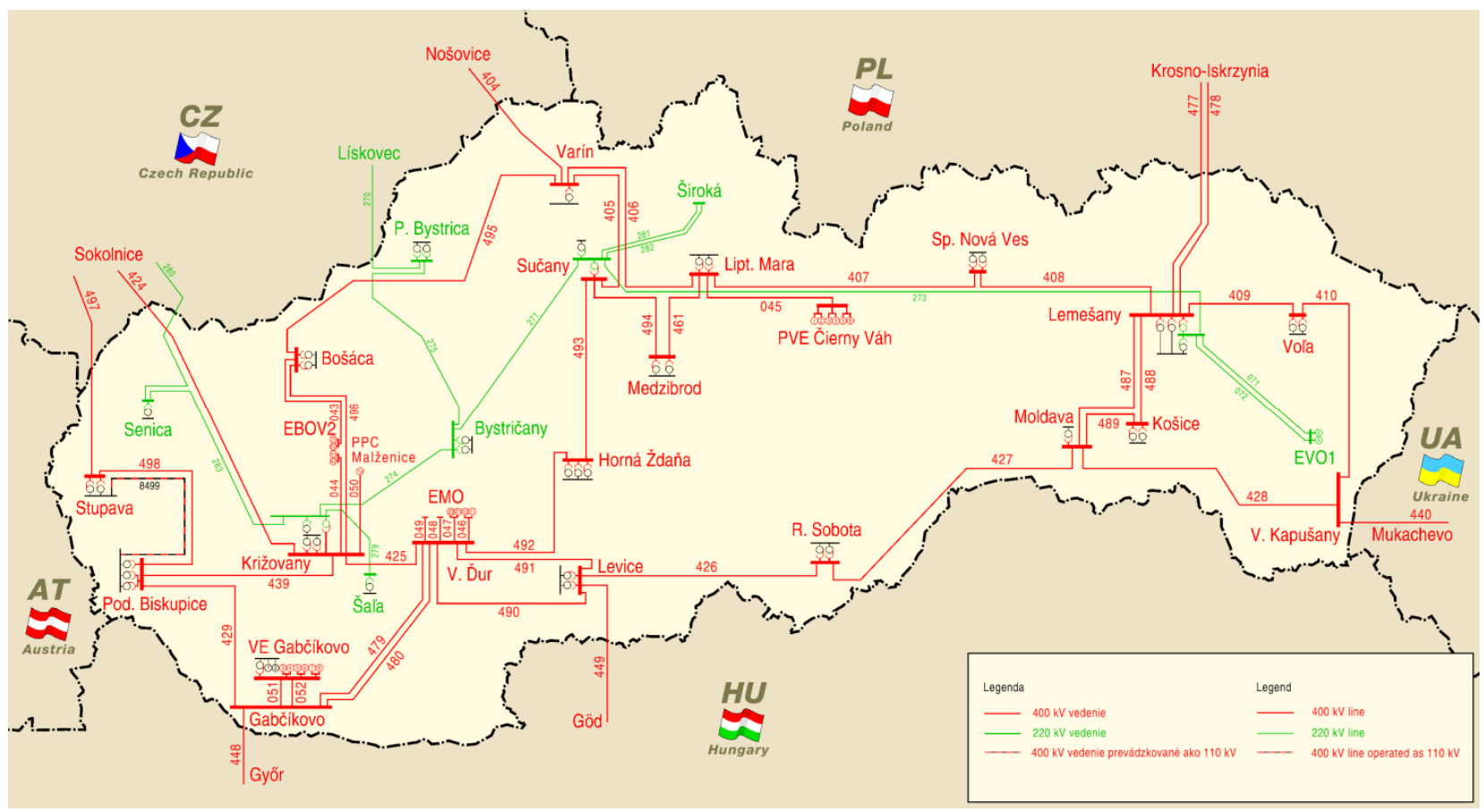

Fig. 1 Transmission power system of Slovak Republic 
The climatic conditions surrounding the power line are not constant. During the day there is a change in ambient temperature, change in the speed and direction of air flow and change in the intensity of solar radiation.

Climatic conditions depend mainly on the season. For months from December to February there is a significant drop in the outdoor temperature compared to other periods during the year. Likewise there is also a change in the intensity of solar radiation. This article solves the difference between the proposed maximum ampacity of the electrical conductors and allowable value of the ampacity during various climatic conditions.

In this article we will examine the difference in the ampacity for the following cases:

- comparison between the ampacity of the electrical conductor with changing intensity of sunlight and the ampacity given by the standard EN 50341,

- comparison between the ampacity of the electrical conductor with changing air velocity and the ampacity value given by the standard EN 50341 ,

- comparison between the ampacity of the electrical conductor with different wind angle of wind and the ampacity value given by the standard EN 50341,

- change in the maximum ampacity of the electrical conductor determined under the standard EN 50341 with changing ambient temperature to the maximum ampacity value.

A rope ACSR 350/59 which is the mostly used conductor in a three-bundle configuration was chosen for the following study. In the first part it is necessary to determine the maximum permissible ampacity of the conductor according to standard EN 50341, which is given by a calculation with constant ambient conditions described in Chapter 2.

\subsection{Impact of changing intensity of sunlight on the ampacity of the electrical conductor}

Solar radiation consists of direct and diffused radiation incident on a surface. The dependence of the maximum permissible current on the change in the intensity of sunlight in the interval $\left(100 \mathrm{~W} / \mathrm{m}^{2}-1000 \mathrm{~W} / \mathrm{m}^{2}\right)$ to the current value given by a standard is examined in this paper. Dependence is shown on the following Fig. 2.

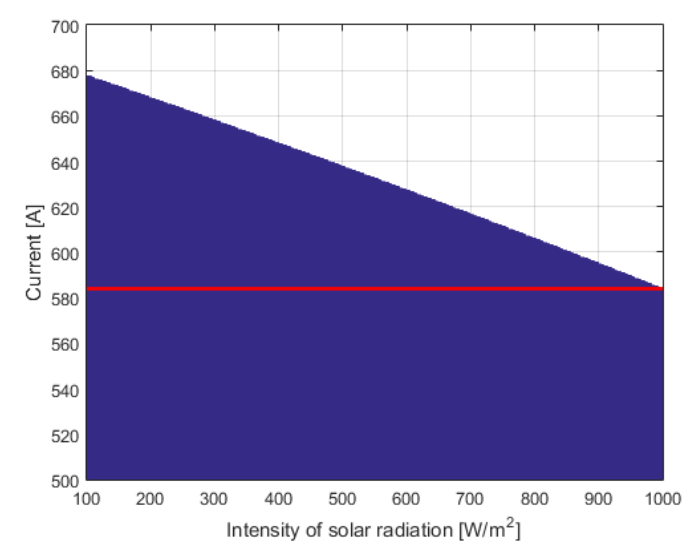

Fig. 2 Comparison of permissible current value in changing the intensity of sunlight
As it is shown in the figure the permissible current value in accordance with the standard EN 50341 is 583.96 A (red line). The maximum current for intensity of solar radiation $100 \mathrm{~W} / \mathrm{m}^{2}$ is $677.78 \mathrm{~A}$. This value is by $16.07 \%$ higher than the value of the ampacity designated by the standard.

For the intensity of solar radiation $1000 \mathrm{~W} / \mathrm{m}^{2}$, the maximum value of permissible current for one conductor in the bundle decreased to $583.96 \mathrm{~A}$, which is value given by a calculation in accordance to the standard.

\subsection{Impact of change in air on the ampacity of the electrical conductor}

Wind conditions in every country are rather variable. The main impact is the variability of the weather during the year. The actual ampacity of ACSR 350/59 conductor under the influence of wind was investigated with changing air velocity in the range from $1 \mathrm{~m} / \mathrm{s}$ to $40 \mathrm{~m} / \mathrm{s}$ with angle of impact $45^{\circ}$. Results from this calculation are in the following figure (Fig. 3).

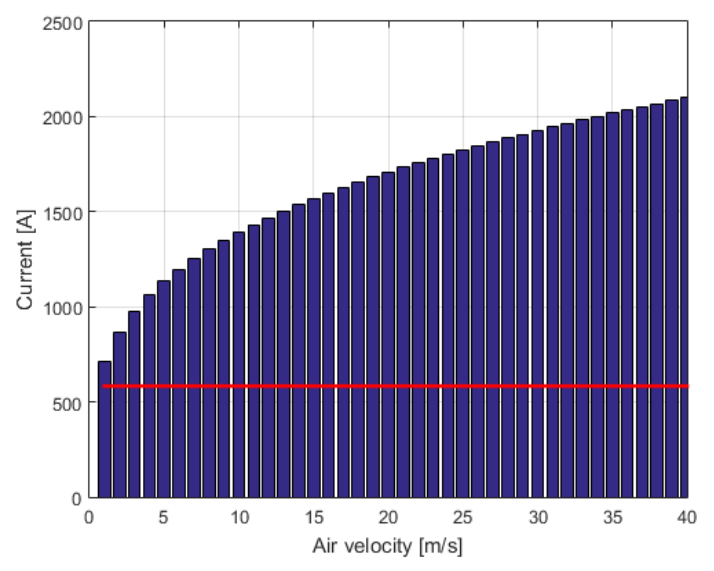

Fig. 3 Comparison of permissible current value in changing the air velocity

The maximum permissible value of ampacity for the cable ACSR 350/59 is 583.96 A (red line). Figure shows that an increase in air velocity involves an increase in ampacity of the conductor. There is a difference in the permissible current by $21.77 \%$ between the value given by the standard EN 50341 and the value calculated for the air velocity $1 \mathrm{~m} / \mathrm{s}$. Permissible value of current is 711.11 A for air velocity $1 \mathrm{~m} / \mathrm{s}$. The difference of ampacity designated for the air velocity $40 \mathrm{~m} / \mathrm{s}$ and according to the standard EN 50341 is $259.56 \%$. Permissible value of the current is 2099.66 A for air velocity $40 \mathrm{~m} / \mathrm{s}$.

\subsection{Impact of the angle change of wind on the electrical conductor ampacity}

Unevenness of heating of the Earth's surface and above-ground layer of air causes inequality of distribution of atmospheric pressure, causing the movement of air masses, thus a wind.

Angle of the wind has a direct impact on the resulting value of capacity. In this case, a study for impact of changing angle of the wind on the resulting value of current for a conductor ACSR 350/59 without amendments of wind speed is provided. Results from this calculation are in the following figure (Fig. 4). 


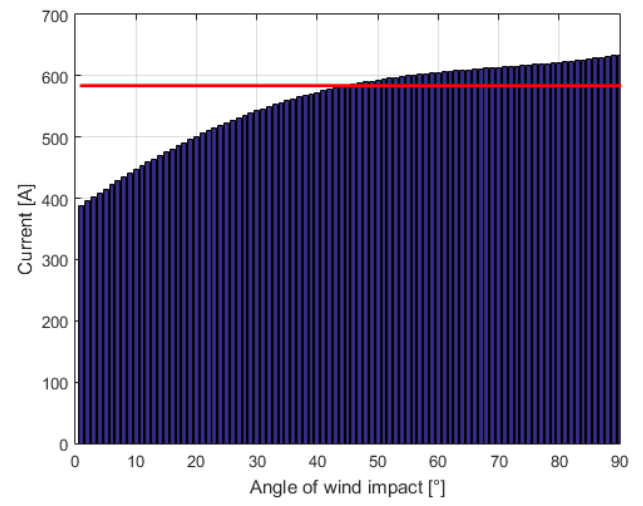

Fig. 4 Comparison of permissible current value in changing the angle of wind impact

Fig. 4 shows, that a change of angle has effect on the permissible ampacity of conductor. For angle of impact $0^{\circ}$ to $15^{\circ}$ the resulting value is lower than a value of current given by a standard. The permissible current is lower by $33.49 \%$ for angle $0^{\circ}$. Resulting value of current is 388.41 A. For the $90^{\circ}$ impact angle of the wind, the ampacity for ACSR conductor is $633.87 \mathrm{~A}$ and difference between the value given by a calculation and value given by the standard is about $8.55 \%$.

\subsection{Ampacity of the electrical conductor for changing ambient temperature}

The air temperature is one of the main factors affecting the actual value of the maximum current.

Two calculations were made for determining the actual value of current. The first calculation was made for negative value of ambient temperature in the range $-40{ }^{\circ} \mathrm{C}$ to $-1{ }^{\circ} \mathrm{C}$. The second calculation was made for positive value of ambient temperature in the range $1{ }^{\circ} \mathrm{C}$ to $40{ }^{\circ} \mathrm{C}$. Results from calculation of permissible value of current based on the ambient temperature are in the Fig. 5, Fig. 6.

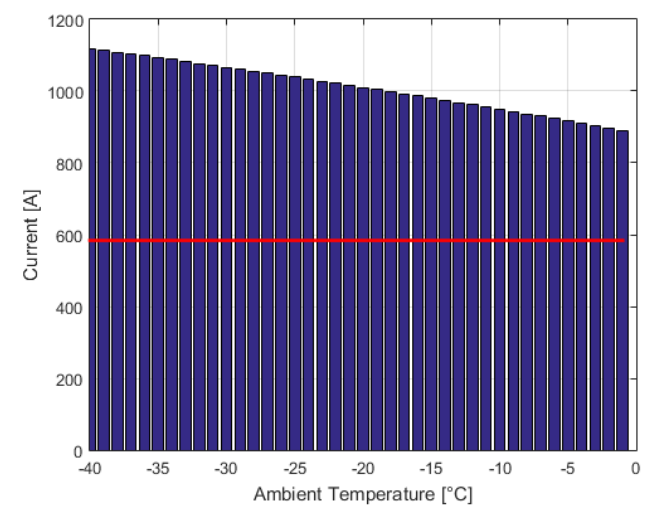

Fig. 5 Comparison of permissible current value in changing the ambient temperature, part I

As it can be seen from the figures above (Fig. 5 Fig. 6 ), during the change of ambient temperature from $-40{ }^{\circ} \mathrm{C}$ to $-1{ }^{\circ} \mathrm{C}$ or from $+1{ }^{\circ} \mathrm{C}$ to $+40{ }^{\circ} \mathrm{C}$ a decrease of the maximum permissible value of current for the conductor ACSR 350/59 occurred.

The maximum permissible current is $1118.75 \mathrm{~A}$ at ambient temperature $-40{ }^{\circ} \mathrm{C}$. Comparing with a maximum permissible value of current given by a standard EN

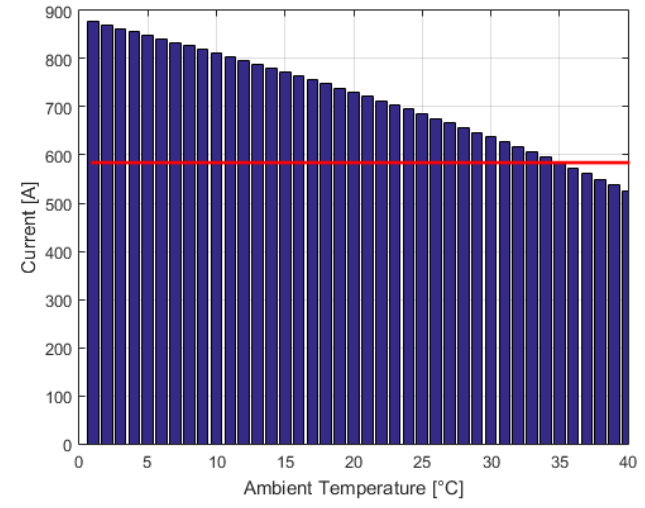

Fig. 6 Comparison of permissible current value in changing the ambient temperature, part II

50341 and maximum current determined from calculation there is a reserve of $91.58 \%$ for overloading an ACSR $350 / 59$ conductor. For ambient temperature $-1{ }^{\circ} \mathrm{C}$ the ampacity is $890.36 \mathrm{~A}$, which is higher about $81.78 \%$ than the capacity given by a standard.

For the second case of ambient temperature in the range from $+1{ }^{\circ} \mathrm{C}$ to $+40{ }^{\circ} \mathrm{C}$ a decrease of ampacity for conductor ACSR 350/59 (Fig. 6) occurred. The maximum current decreased from 876.76 A to 525.20 A. Comparing with the maximum current calculated with a standard EN 50341 the difference was from $50.14 \%$ to $-10.06 \%$.

\section{DISCUSION AND CONCLUSION}

Power lines as part of power system ensure a transfer of electricity. They consist of the transmission and distribution power lines. Operation of the transmission power lines is limited with the maximal allowable current value that can be transmitted through the conductors. This allowable value is limited by properties of the conductor and ambient conditions.

Construction of the power lines must be performed in accordance with a standard. For the extra high voltage system a standard EN 50341 was issued. Ambient conditions for the calculation of the power line ampacity are described in this standard.

As it is known, the ambient conditions are not constant. They are variable in the time. In many cases the environment does not reach a critical conditions given by a standard.

The aim of this article was to examine the influence of the ambient conditions to the maximum current value. The ambient conditions that influenced the resulting value of current are intensity of solar radiation, air velocity, angle of wind impact and ambient temperature. Results from the study of environmental influence on the capacity of power lines are described in this article. On the other hand, given results represent a possibilities to operate a transmission lines on the higher value as is given in the proposed project.

\section{ACKNOWLEDGMENTS}

Research described in the paper was supported by the Ministry of Education, Science, Research and Sport of the Slovak Republic and the Slovak Academy of Sciences under the contract No. VEGA 1/0132/15. 


\section{REFERENCES}

[1] PIERNOT, S. J. - LEAHY, J.: Maximize the capacity of your transmission lines, Transmission and Distribution Conference and Exposition, IEEE/PES, Atlanta, GA, Vol. 1, pp. 391-396, 2001.

[2] THE ALUMINUM ASSOCIATON - Aluminum Electrical Conductor Handbook, 2nd ed. Washington, DC, 1982.

[3] WORKING GROUP B2.12.: Guide for selection of weather parameters for bare overhead conductor rating, CIGRE, 2006.

[4] IEEE POWER ENGINEERING SOCIETY: IEEE standard for calculating the current temperature of bare overhead conductors, 2007.

[5] BRACALE, A. - ANDREOTTI, A. CARPINELLI, G. - DE MARTINIS, U.: Probabilistic index for increasing hourly transmission line rating, International Journal of Emerging Electric Power Systems, Vol. 8, Iss. 4, 2007.

[6] CARRERAS, B. B.: Evidence for self-organized criticality in a time series of electric power system blackouts, IEEE Transaction on Circuits and Systems - I: REGULAR PAPERS, Vol. 51, No. 9, 2004.

[7] CIGRE TASK FORCE B2.12.3.: Sag-tension Calculation Methods for Overhead Lines, Technical Brochure 324, 2007.

[8] CIGRE WORKING GROUP B2.12.: Alternating Current (AC) Resistance of Helically Stranded Conductors, Technical Brochure 345, 2008.

[9] CIGRE WORKING GROUP B2.12.: Thermal Behaviour of Overhead Conductors, Technical Brochure 207, 2002.

[10] ŠPES, M. - BEŇA, L. - MIKITA, M. - MÁRTON, M. - WACHTA, H.: Possibilities of increasing transmission capacity overhead lines, In: Acta Electrotechnica et Informatica, Vol. 16, No. 3, 2016, pp. 20-25, ISSN 1335-8243.

[11] EN 50341-1 ed. 2: Overhead electrical lines exceeding AC $1 \mathrm{kV}$ - Part 1: General requirements Common specifications.

[12] FECKO, Š. - ŽIARAN, J. - VARGA, L.: Elektrické siete - Vonkajšie silové vedenia, SVŠT Bratislava, 1990.

Received April 7, 2017, accepted July 11, 2017

\section{BIOGRAPHIES}

Michal Špes was born in 1991. In 2015 graduated (MSc) at the department of electric power engineering. At present is a Ph.D. student in the Department of Electrical Power Engineering on the Faculty of Electrical Engineering and Informatics at Technical University of Košice. He received a master degree in electric power engineering on subject evaluation of generator exciting outage. His scientific research is mainly focused on research of powerline ampacity system.
Lubomír Beňa was born in 1975 in Bardejov, Slovakia. In 1998 he graduated (MSc) at the Department of Electrical Power Engineering, Faculty of Electrical Engineering and Informatics, TU of Košice. He defended his $\mathrm{PhD}$. in the field of overhead power lines mechanics in 2001. Since 2010 he is associated professor at the Department of Electrical Power Engineering. His scientific research is analysis of electrical power systems and optimization problems in electrical power engineering.

Michal Kosterec was born on 26.2.1990. In 2014 graduated (MSc) at the Department of Electrical Power Engineering on the Faculty of Electrical Engineering and Informatics at TU of Košice. At present is a Ph.D. student in the Department of Electrical Power Engineering on the Faculty of Electrical Engineering and Informatics at TU of Košice. He received a master degree in electric power engineering on subject advanced simulation techniques as tool for current problems in the electric power engineering solution.

Lukáš Kruželák was born in 1990. In 2015 graduated (MSc) at the department of electric power engineering. At present is a Ph.D. student in the Department of Electrical Power Engineering on the Faculty of Electrical Engineering and Informatics at TU of Košice. He received a master degree in electric power engineering on subject evaluation investigate the dielectric properties of magnetic fluids. His scientific research is mainly focused on research of electrophysical process analysis in high voltage insulation materials.

Zdeněk Müller is head of Department of Electrical Power Engineering at Faculty of Electrical Engineering, CVUT Prague. His expertise and research projects are Intelligent System for Safe and Reliable Electrical Energy Supply in a Region (2014-2017, TA), Local Automation in WAMPaC Systems (2014-2016, SGS), Research and Development of Effective CHP Generation (2012-2014, FR-TI4), Nonlinear Dynamic Loads Negative Effects Mitigation (2013-2016, TA), Local automation in transmission systems, Smart Region Architecture, AMM infrastructure application possibilities and AMM data processing, WAMS applications in transmission systems, Protection system optimization.

Henryk Wachta was born in 1964 in Przemysl, Poland. In 1993 he graduated (MSc) at the Department of Power Electronics and Power Engineering, Faculty of Electrical and Computer Engineering, Rzeszow University of Technology. He defended his PhD. in the field of lighting technology in 2004 at the Warsaw University of Technology. Since 2004 he is lecturer at the Department of Power Electronics, Power Engineering and Complex Systems at the Rzeszow University of Technology. His scientific research is construction of luminaires and luminaires work in the electrical installation.

Michal Márton was born in 1992. In 2016 graduated (MSc) at the Department of Electronics and Multimedia Telecommunications. At present is a Ph.D. student in the Dep. of Electronics and Multimedia Telecommu-nications on the Faculty of Electrical Engineering and Informatics at TU of Košice. He received a master degree in multimedia telecommunications on measurement with the fibre optic gyroscope system. His scientific research is mainly focused on research of optical communications. 